\title{
How successful are women's groups in health promotion and disease prevention? A synthesis of the literature and recommendations for developing countries
}

S. Akhund ${ }^{7}$ and A.K. Yousafzai ${ }^{2}$

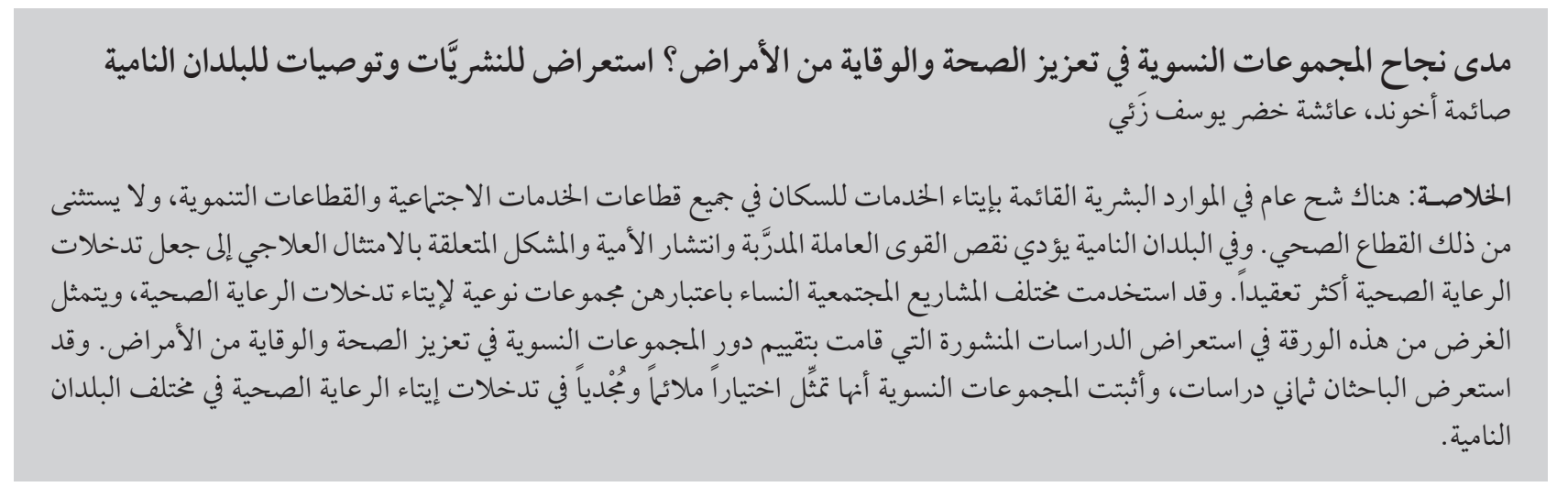

ABSTRACT There is a general scarcity of resources for delivery of services to the population in all social welfare and development sectors, with the health sector being no exception. In developing countries, lack of trained manpower, illiteracy and compliance issues make health care interventions even more complex. Various community-based projects have used women as a specific group for delivery of health care interventions. The objective of this paper was to review published studies that evaluated women's groups for the promotion of health and prevention of disease. A total of 8 studies were reviewed. Women's groups have proved to be a convenient and workable option for delivering health care interventions in several developing countries.

Dans quelle mesure les associations de femmes contribuent-elles à la promotion de la santé et la prévention des maladies ? Synthèse de la littérature et des recommandations en provenance des pays en développement

RÉSUMÉ Le manque de ressources est généralisé pour la prestation de services à la population dans tous les secteurs de la protection sociale et du développement, secteur de la santé inclus. Dans les pays en développement, le manque de personnel qualifié, I'analphabétisme et les problèmes d'observance rendent les interventions sanitaires encore plus complexes. Une grande variété de projets communautaires a eu recours à des associations composées de femmes dédiées à la prestation d'interventions de soins de santé. L'objectif du présent article était d'analyser les études publiées sur les associations de femmes œuvrant pour la promotion de la santé et la prévention des maladies. Au total, huit études ont été analysées. Les associations de femmes se sont révélées être une option pratique et réalisable pour la prestation d'interventions sanitaires dans plusieurs pays en développement. 


\section{Introduction}

Community participation has been considered as a cornerstone of the primary health care approach ever since the Alma-Ata declaration in the late 1970s [1]. Its benefits in term of health programmes - including efficiency, effectiveness, equity and improved coverage and self-reliance - are well documented [2]. Recently, community participation has regained attention in the public health intervention agenda due to the general lack of resources devoted to services at the primary health care level [3].

One paradigm of community participation in health research is communitybased participatory research (CBPR), in which community members and researchers work together to achieve improved health outcomes $[4,5]$. The major benefit of this approach is that it empowers local people to develop confidence and it promotes community cohesion [6]. Some uses of CBPR interventions in the health arena include the development of referral systems, empowerment of female community health volunteers, provision of health services to remote communities and prevention of substance abuse [7-10]. A recent systematic review from the United States of America in the field of occupational and environmental health has found that CBPR led to community level action to protect and improve the health of the community in 14 out of 20 studies reviewed [11].

The extent of involvement of communities in CBPR may vary depending on the research objectives [12]. It may range from exploring perceptions of community members on certain issues, problem identification and prioritization, data collection, analysis and interpretation, to design, implementation and evaluation of interventions [13-16]. Action research approaches often aim to include service users and communities in both the delivery of health interventions and in research projects. Specific user alliances may be formed in order to develop more focused strategies and to cater to the needs of the members of society whose voices are least heard, such as women and children [17].

Group formation has a great potential to enable its members to achieve their goals. Experience has shown that women's support groups respond best to participatory, non-didactic approaches that encourage group members to share knowledge and work together. In an extensive review of mother's support groups, Green has identified several types of groups that are or could be connected to child health and survival [18]. These include microcredit groups, breastfeeding support groups, mothers' clubs, literacy classes, community day care centres, water and sanitation committees, forestry cooperatives and social and political groups [18]. Examples of groups comprising exclusively women that have achieved their goals come from various parts of the world, including African, Latin American and Asian countries where these groups are mostly involved in breastfeeding support, forestry interventions and income generation activities [18-22]. However, considering the ability of women to understand and communicate with other women, especially with women of the same community, the utility of women's groups in other areas of health is being increasingly investigated [23-25].

There is a general scarcity of resources for delivery of services to the population in all social welfare and development sectors, with the health sector being no exception. Constraints in finding trained manpower and problems of accessibility, illiteracy and compliance make health care interventions even more difficult to administer and sustain in developing countries. In this context various community-based projects have used women as a particular community group for delivery of interventions, principally because they ensure access to other women in a culturally relevant way and provide a cost-effective, sustainable service that responds to the community's need. In this paper we review studies published from 1998 to 2008 that used groups primarily composed of women and that were geared towards delivering interventions related to health care.

\section{Literature search}

A literature search, largely of the peerreviewed literature, was done from the PubMed database, a hand search of library periodicals and a search of relevant reports by the World Health Organization and other international agencies published over the period 1998-2008. The keywords used were: community participation, women's groups, developing countries, health promotion, disease prevention, primary health care and action research. Studies that involved interventions using women on an individual (rather than a group basis) were not included in the analysis. We also included studies that were cross-sectional and descriptive in nature but that described the use or effectiveness of women's group on any health-related outcomes. Studies of women's groups organized around microcredit programmes but with an educational or community health component were also included in the review. Studies reporting simply on delivery of information or health education to participants without reporting any interaction/discussion among the group members were excluded.

\section{Evidence}

We made a detailed review of 8 studies that demonstrated the efficacy of women's group interventions for the improvement of reproductive and neonatal health outcomes in different parts of the world [26-33]. These are summarized in Annex 1 (available 
online). The study designs ranged from basic descriptive studies of organizing women's groups to sophisticated randomized controlled trials. More trial protocols have been published recently which aimed to adapt a similar community mobilization approach via women's groups for improving mother and child health in Andhra Pradesh and Mumbai, India $[34,35]$. We have found that some of the groups were established specifically around health outcomes, whereas others had a different goal but were successful in improving health outcomes, such as in the case of microcredit schemes.

In the various researches conducted on the topic, women's groups were usually convened and guided with the help of community-based local facilitators, such as auxiliary nurses, local women trained as counsellor/supervisors or community health workers. The task of the facilitator was to convene the group and guide its activities. Some of the health-related topics covered in the women's groups included promotion of family planning, prevention and management of malaria, breastfeeding (initiation, colostrum giving, exclusive breastfeeding, start of weaning and solving problems related to breastfeeding), prevention and management of diarrhoea, and antenatal, natal, postnatal and neonatal care.

Collaboration with the community where the group has to function was mostly accomplished at the conceptualization phase of the interventions. The literature from developed countries has identified certain factors that make this collaboration effective [36-38]. It is of utmost importance to recognize and appreciate the community's contributions, no matter how small these are. This acknowledgement creates a sense of ownership for the group by the relevant community. Similarly, clear and open lines of communication are desirable attributes of a successful group. Any task that requires particular skills means that the group members need to be empowered with the required skills. Mutual trust and respect are vital to achieving strong ties with the community. Power dynamics also need be considered. Projects that follow only a top-down approach are seldom successful; it is the sharing and balancing of power that plays a crucial part in group success. Conflict and disagreement are very natural when a group of people work together and are especially likely to occur if people outside the community enter it with different research and development agendas. It is vital to recognize that conflict may occur between the group and the community and efforts are required to contain it.

A number of activities are reported in the scientific literature that could be performed by women's group [18,19,24,25,27,31,32,39-42] (Box 1). Not only does the community for which the women's group work gain from its activities but the group members themselves accrue certain benefits as a result of participation in the group (Box 2) [6, $8,12,13,15,18,28,32,33,40,41,43]$.

If we define success as improvement in the outcome as a result of women's group intervention and continuing activity of the group even after the end of study period, different factors have been found conducive to the success of such groups. While in a few studies group homogeneity was believed to be a successful attribute $[18,43]$, others found that group ethnic and social diversity was the key to success [44]. The support

\section{Box 1 Examples of activities performed by women's groups}

- Training community members in safe birthing techniques.

- Generation of community funds for maternal and infant care.

- Stretcher provision schemes.

- Production and distribution of clean delivery kits.

- Home visits by women's group members to newly pregnant mothers.

- Awareness raising with the help of video films.

- Social and psychological support.

- Income generation.

- Improvement of water supply and sanitary conditions including chlorination of village well water.

- Support for early initiation and maintenance of breastfeeding.

- Literacy classes.

- Skills development training (e.g. in forestry, small business development skills).

- Seek government assistance (e.g. in forestry cooperation).

- Management of diarrhoeal diseases (e.g. preparation of sugar salt solution, hand washing etc.). 
- Knowledge enhancement.

- Skills development.

- Empowerment.

- Emotional support.

- Financial support.

- Lessening of stigma (by knowing that others have similar problems).

- Self-satisfaction (if helping other members of the group/community).

- Validation of care-giving experiences.

- Reduction in tension and guilt.

- Community ownership and participation versus didactic education.

of husbands was sometimes a factor necessary for the group's success [45]. Supervisor support and good rapport with the community was also important [28].

Box 3 shows some suggested steps for initiation and running of a women's group.

\section{Discussion}

An active alliance between communities and researchers is vital for developing appropriate public health research strategies that address community needs [36]. Group formation has a great potential to empower, generate income and improve the health status of poor people, especially women [46].
Empowerment is a well-recognized benefit that accrues to women as a result of group participation. Multiple levels and domains of empowerment have been identified in this connection, at the psychological, organizational and community level and within households, programmes and services (such as water, health and education) and the political, legal and economic spheres. Interventions that empower women and that are integrated with the educational, economic and political sectors have shown the greatest impact on women's quality of life, autonomy and authority in various matters and on the improvement of child and family health $[18,30,47]$.

Selected case studies from India have found that members of women's groups reported improvements in their lives, such as being able to go out of the house, participation in village political life, interaction with officers of various government departments, a greater role in family decision-making and an influence in their own community by advocating on social issues such as road maintenance, child labour, water supply and education [48]. Similarly, a number of impressive examples of women's empowerment come from the Tawana project in Pakistan, which focused on community participation and empowerment through decision-making at the school committee level (comprising mothers, other community women, teachers and girl students) [30]. For instance, many of the women obtained a national identity card for the first time,

Box 3 Suggested steps for initiation and running of a women's group

- Background work: if the group has to be started on a voluntary basis.

- Identification of a group facilitator.

- Formulation of a women's group.

- Problem identification.

- Priority setting.

- Planning strategies.

- Implementing strategies.

- Monitoring and evaluation 
opened and operated a bank account for the first time, and went out of their villages for the first time. Women interacted with district government officials on several occasions, demanding release of funds for the purchase and preparation of food items for the nutritional programme for schoolgirls.

Success of basic health promotion and disease prevention interventions by women's groups pave the way for other health interventions to be delivered by the groups and hence the scope of services provided by community women's groups can increase. A recent cluster randomized controlled trial from Australia found positive effects of support by mother advocates in delivering intimate partner violence interventions to women [49]. However, caution should be exercised when replicating successful models from developed countries to developing ones [50].

Although not thefocus of this review, some of the other models of support by women in the community also deserve consideration. For example, where group formation is not possible due to the unavailability or lack of interest of community women to form groups, support may be provided by women on a one-to-one basis. Studies from several countries have documented the encouraging contributions of doulas, women experienced in childbirth, who provide continuous physical, emotional and informational support to women before, during and just after childbirth [39,40,51].

In patriarchal societies, women's groups alone may not be the sole intervention for improving health outcomes. In these countries, women's groups, along with groups of respected and influential village members and adolescent's groups, may augment the achievement of healthrelated objectives for specific communities. In a recent study from India, Dongre et al. were successful in mobilizing the community for improved care-seeking for mothers of newborns by using a multitude of groups from the community including women's groups, farmer's group, a village coordination committee and adolescents' groups [52].

In another interesting development, which hinges on the advancement of information technology, various channels of communication have been used for the provision of advice and support to disadvantaged groups in communities. These include peer support telephone calls and computer-mediated support groups $[41,53,54]$. In future, similar types of expansion of the methods used by women's group may also be possible in developing countries. However, until such time they must rely primarily on visiting people in person.

In order to tackle issues of sustainability, another important dimension worth exploring would be integration of women's group into government health systems, which often suffer accessibility barriers that may be geographical, sociocultural or financial. A model for such an experiment is the National Program for Family Planning and Primary Health Care, which is a state sponsored programme with 96000 "lady health workers" providing health services directly to Pakistani women's homes [55]. Each lady health worker is responsible for organizing the community by developing women's groups and health committees in her catchment area and it is worth exploring the degree to which of the groups are functional and what kind of impact they have on the health and well being of community people.

Cost-effectiveness analysis was available for only one study (the Nepal Makwanpur trial) which found the women's group intervention was a cost-effective means of reducing neonatal mortality [56]. Another study assessing the cost of group meetings in comparison with individual visits found the cost of group meetings was lower than home visits [42].

\section{Conclusion \& Recommendations}

There is substantial evidence that women's groups are success in achieving their objectives at least on a short-term basis. Longer-term follow-up studies are needed to evaluate the sustainability of such alliances. Women's groups help individuals, families and communities. Considering the scarcity of resources, poorly functioning health systems and widespread poverty in many developing countries, we recommend that this powerful alliance could be used for improving mother and child outcomes and could also be expanded to other public health intervention strategies, such as the integrated management of childhood illnesses, early childhood development and polio eradication.

\section{Acknowledgements}

The authors wish to thank Dr Ali Khan Khuwaja, Assistant Professor, Department of Family Medicine, Aga Khan University, Karachi for his careful review of the manuscript and valuable feedback.

\section{References}

1. Declaration of Alma-Ata, 1978. International Conference on Primary Health Care, Alma-Ata, USSR, 6-12 September 1978. Geneva, World Health Organization, 1978,

2. Community involvement in health development: challenging health services. Geneva, World Health Organization, 1991 (WHO Technical Report Series No. 809).
3. World health report 2004. Community participation: advocacy and action. Geneva, World Health Organization, 2004.

4. Green LW et al. Study of participatory research in health promotion: review and recommendations for the development of participatory research in health promotion in Canada. British Columbia, Institute of Health Promotion Research, the University 
of British Columbia and the BC Consortium for Health Promotion Research for the Royal Society of Canada, 1995.

5. Israel BA et al. Community-based participatory research: policy recommendations for promoting a partnership approach in health research. Education for Health, 2001, 14:182-197.

6. Purdey AF et al. Participatory health development in rural Nepal: clarifying the process of community empowerment. Health Education Quarterly, 1994, 21:329-343.

7. Edwards N, Roelofs S. Participatory approaches in the codesign of a comprehensive referral system. Canadian Nurse, 2005, 101:20-24.

8. Shrestha S. A conceptual model for empowerment of the female community health volunteers in Nepal. Education for Health, 2003, 16:318-327.

9. Minore B et al. Addressing the realities of health care in northern aboriginal communities through participatory action research. Journal of Interprofessional Care, 2004, 18:360-368.

10. Marcus MT et al. Community-based participatory research to prevent substance abuse and HIV/AIDS in African-American adolescents. Journal of Interprofessional Care, 2004, 18:347359.

11. Cook WK. Integrating research and action: a systematic review of community-based participatory research to address health disparities in environmental and occupational health in the USA. Journal of Epidemiology and Community Health, 2008, 62:668-676.

12. Howard-Grabman L, Snetro G. How to mobilize communities for health and social change. Washington DC, John Hopkins University Centre for Communication Programs and Save the Children Federation, 2002.

13. Rosato M et al. Women's groups' perceptions of maternal health issues in rural Malawi. Lancet, 2006, 368:1180-1188.

14. Israel BA et al. Review of community-based research: assessing partnership approaches to improve public health. Annual Review of Public Health, 1998, 19:173-202.

15. Macaulay AC et al.; North American Primary Care Research Group. Participatory research maximises community and lay involvement. British Medical Journal, 1999, 319:774-778.

16. Reason $\mathrm{P}$, Bradbury $\mathrm{H}$, eds. Handbook of action research. London, Sage Publications, 2001.

17. Osrin D et al. Implementing a community-based participatory intervention to improve essential newborn care in rural Nepal. Transactions of the Royal Society of Tropical Medicine and Hygiene, 2003, 97:18-21.

18. Green CP. Mother support groups: a review of experience in developing countries. Arlington, Virginia, Basic Support for Institutionalizing Child Survival (BASICS) Project, 1998.

19. Green CP. Improving breast feeding behaviors: evidence from two decades of intervention research. Washington DC, LINKAGES Project, Academy for Educational Development (for the United States Agency for International Development), 1999.

20. Increasing fisherfolk incomes through group formation and enterprise development in Indonesia. Madras, India, Bay of Bengal Programme, 1993.

21. Ardner S, Burman S. Money-go-rounds: the importance of rotating savings and credit associations for women. Oxford, Berg Publishers, 1995.

22. Evans TG et al. Demystifying Nonparticipation in microcredit: A population-based analysis. World Development, 1999, 27:419-430.

23. Hartley S et al. Women in action. Improving the quality of disabled children's lives. Banglore, National Printing Press, 2005.

24. Howard-Grabman L, Seoane G, Daven C. The Warmi Project: $a$ participatory approach to improve maternal and neonatal health, an implementer's manual. Arlington, Virginia, MotherCare/ USAID, 1992

25. Bhuiya A, Chowdhury M. Beneficial effects of a womanfocused development programme on child survival: evidence from rural Bangladesh. Social Science \& Medicine, 2002, 55:1553-1560.

26. Kouyaté B et al. Process and effects of a community intervention on malaria in rural Burkina Faso: randomized controlled trial. Malaria Journal, 2008, 7:50.

27. O'Rourke K, Howard-Grabman L, Seoane G. Impact of community organization of women on perinatal outcomes in rural Bolivia. Pan American Journal of Public Health, 1998, 3:9-14.

28. Morrison J et al. Women's health groups to improve perinatal care in rural Nepal. BMC Pregnancy and Childbirth, 2005, 5:6.

29. Gibbon M, Cazottes I. Working with women's groups to promote health in the community using the Health Analysis and Action Cycle within Nepal. Qualitative Health Research, 2001, 11:728-750.

30. Tawana Pakistan: a project of the Ministry of Social Welfare and Special Education. Government of Pakistan project report. Karachi, Hamdard Press, 2006.

31. Dearden $\mathrm{K}$ et al. The impact of mother-to-mother support on optimal breast-feeding: a controlled community intervention trial in peri-urban Guatemala City, Guatemala. Pan American Journal of Public Health, 2002, 12:193-201.

32. Mohindra KS, Haddad S, Narayana D. Can microcredit help improve the health of poor women? Some findings from a cross-sectional study in Kerala, India. International Journal for Equity in Health, 2008, 7:2

33. Hadi A. Promoting health knowledge through micro-credit programmes: experience of BRAC in Bangladesh. Health Promotion International, 2001, 16:219-227.

34. Boone $\mathrm{P}$ et al. Community health and medical provision: impact on neonates (the CHAMPION trial). BMC Pediatrics, $2007,7: 26$

35. More NS et al. Cluster-randomised controlled trial of community mobilisation in Mumbai slums to improve care during pregnancy, delivery, postpartum and for the newborn. Trials, 2008, 9:7.

36. Koné A et al. Improving collaboration between researchers and communities. Public Health Reports, 2000, 115:243-248.

37. Parker EA et al. Coalition building for prevention: lessons learned from the North Carolina Community-Based Public Health Initiative. Journal of Public Health Management and Practice, 1998, 4:25-36.

38. Baker EA et al. Principles of practice for academic/practice/ community research partnerships. American Journal of Preventive Medicine, 1999, 16(Suppl.):86-93.

39. Klaus $\mathrm{MH}$ et al. Effects of social support during parturition on maternal and infant morbidity. British Medical Journal, 1986, 293:585-587.

40. Langer A et al. Effects of psychosocial support during labour and childbirth on breastfeeding, medical interventions, and mothers' wellbeing in a Mexican public hospital: a randomised clinical trial. British Journal of Obstetrics and Gynaecology, 1998, 105:1056-1063.

41. Dennis CL et al. Effect of peer support on prevention of postnatal depression among high risk women: multisite randomised controlled trial. British Medical Journal, 2009, 338:a3064.

42. Chowdhury AM, Karim F, Ahmed J. Teaching ORT to women: individually or in groups? Journal of Tropical Medicine and $\mathrm{Hy}$ giene, 1988, 91:283-287.

43. Asthana S. Women's health and women's empowerment: a locality perspective. Health and Place, 1996, 2:1-13. 
44. Manandhar DS et al.; Members of the MIRA Makwanpur trial team. Effect of a participatory intervention with women's groups on birth outcomes in Nepal: cluster-randomised controlled trial. Lancet, 2004, 364:970-979.

45. Howard Grabman L. Reasons some women participate in local organizations and others don't. Washington DC, Save the Children, 1998.

46. Thorp R, Stewart F, Heyer A. When and how far is group formation a route out of chronic poverty? World Development, 2005 33:907-920

47. Wallerstein N. What is the evidence on effectiveness of empowerment to improve health? Copenhagen,World Health Organization Regional Office for Europe, 2006 (Health Evidence Network report).

48. Kilby P. Questioning empowerment: lessons from women's groups in India. Participatory Development Working Papers No. 06/03. Canberra, Australia, Australian National University, 2006 (http://asiapacific.anu.edu.au/maapd/papers/wp-0603.pdf, accessed 24 March 2011).

49. Taft AJ et al. MOSAIC (Mothers' Advocates In the Community): protocol and sample description of a cluster randomised trial of mentor mother support to reduce intimate partner violence among pregnant or recent mothers BMC Public Health, 2009, 27:159.
50. Neonatal Mortality Formative Research Working Group. Developing community-based intervention strategies to save newborn lives: lessons learned from formative research in five countries. Journal of Perinatology, 2008, 28(Suppl. 2):S2-S8.

51. Hodnett ED, Osborn RW. A randomized trial of the effects of monitrice support during labor: mothers' views two to four weeks postpartum. Birth, 1989, 16:177-183.

52. Dongre AR, Deshmukh PR, Garg BS. A community based approach to improve health care seeking for newborn danger signs in rural Wardha, India. Indian Journal of Pediatrics, 2009, 76:45-50.

53. Dale J et al. Peer support telephone calls for improving health. Cochrane Database of Systematic Reviews, 2008, 8:CD006903.

54. Bragadóttir H. Computer-mediated support group intervention for parents. Journal of Nursing Scholarship, 2008, 40:32-38.

55. Programme evaluation. National Programme for Family Planning and Primary Health Care [website]. Islamabad, Ministry of Health, Government of Pakistan (http://www.phc.gov.pk, accessed 23 March 2011)

56. Borghi J et al. Economic assessment of a women's group intervention to improve birth outcomes in rural Nepal. Lancet, 2005, 366:1882-1884.

\section{EMRO gender and health activities: Increasing the productive involvement of women and girls in society for maximizing health outcomes}

The promotion of greater involvement of women in decision-making and equal access to information and learning opportunities, including access and utilization of health resources, is a key component to the work in gender and health. The link between women's empowerment and resulting better health outcomes for women and their families must be made more explicit. WHO activities in this regard include:

- Sustainable capacity building of women and men in low income communities

- WHO 5 Keys to Safer Food adapted to women at the community level

- Increasing health literacy in semi to illiterate low income women

- Targeting youth to stop the cycle of violence against women.

Further information is available at: http://www.emro.who.int/ghd/index.htm 